\title{
Influence of Welding Variables on Indentation Depth in Ultrasonically Welded Al/Cu Dissimilar Joints and Theoretical Fracture Load Estimation
}

\author{
Minjung Kang* and Kyuhong Lee**,, \\ *Joining R\&D group, Korea Institute of Industrial Technology, Incheon, 21999, Korea \\ **Department of Mechanical Engineering, Incheon National University, Incheon, 22012, Korea \\ †Corresponding author:kmj1415@kitech.re.kr \\ (Received December 9, 2019 ; Revised February 12, 2020 ; Accepted March 9, 2020)
}

\begin{abstract}
Despite increasing industrial demand, typical fusion welding of aluminum and copper joints remains difficult due to the formation of intermetallic compounds. Therefore, ultrasonic welding, which is a type of solid-state welding, is used for combining aluminum and oxygen-free copper. It has a low dependence on the materials and can secure large bonding joints in a short duration. However, indentations formed due to the vibration and pressure of ultrasonic welding greatly impact joint quality by affecting joint strength and fracture location.

This study investigated the formation of indentations in accordance with welding variables, and proposed a theoretical estimation of fracture strength in ultrasonic welded joints of aluminum and oxygen-free copper. Since the fracture occurred along the indentation boundary in aluminum substrate-which has lower strength than copper-failure strength increased with increasing indentation depth in the copper plate. Average fracture strength was $65 \%$ of the tensile strength of base materials due to the stress concentrated around the indentation. Therefore, product design needs to consider base material strength and fracture propagation path before deciding on a safety factor.
\end{abstract}

Key Words : Ultrasonic welding, Welding variable, Indentation depth, $\mathrm{Al} / \mathrm{Cu}$ dissimilar joint, Theoretical strength

\section{Introduction}

The spread of electric and hybrid vehicles is accelerating $^{1)}$, with research for enhancing the mileage per charge being strategically conducted by increasing battery density and efficiency. In battery assembly, a large number of battery cells are connected through tabs or bus-bars, and aluminum and oxygen-free copper are selectively applied according to the type of polarity ${ }^{2,3)}$. Joining processes like electric resistance welding, ultrasonic welding, laser welding, and mechanical fastening 4-6) are used to connect the battery tabs or the lead and tab. Among them, ultrasonic welding is typically used when connecting 30-50 sheets of ultra-thin plates. It has low dependence on the materials and can secure large bonding joints in a short duration, since ultrasonic welding is a solid-state welding technique. Ultrasonic welding proceeds through the steps of clamping, vibration, and unloading, as shown in Fig. 1. Indentations formed by the applied pressure and vibration of the process affect joint strength and fracture location ${ }^{7}$. Particularly, the shape of the horn and anvil affects the joint quality because it directly contacts the substrate ${ }^{7-10)}$. This study investigates the change in indentations according to welding variables and analyzes the correla-

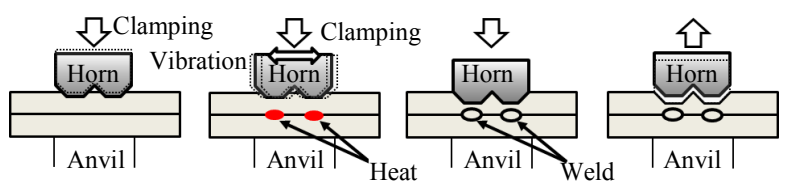

(a)

(b)

(c)

(d)

Fig. 1 Steps in the ultrasonic welding process: (a) Clamping, (b) Vibration and welding, (c) Holding, and (d) Unloading ${ }^{7)}$ 
tion between welding variables and indentation depth. This study also attempts to predict the maximum theoretical fracture strength.

\section{Experimental Method}

Overlapping plates of $0.2 \mathrm{~mm}$ thick non-coated C1020 and Al1050 material were ultrasonically welded. The C1020 showed an average tensile strength of $461 \mathrm{MPa}$, and the Al1050-H18 was $181 \mathrm{MPa}$. As shown in Fig. 2 (a), the materials were machined to a width of $50 \mathrm{~mm}$ and a length of $80 \mathrm{~mm}$. The copper material was placed on the top, and the aluminum was placed at the bottom. The overlap length was $25 \mathrm{~mm}$. The knurl of the anvil and horn had a height of $0.22 \mathrm{~mm}$. Figs. 2 (b) and (c) show the experimental equipment and dimensions of the horn and anvil, respectively.

Welding time, clamping pressure, and amplitude were varied as shown in Table 1 to investigate the influence of these process variables on indentation formation. An optical microscope was used to measure the width and

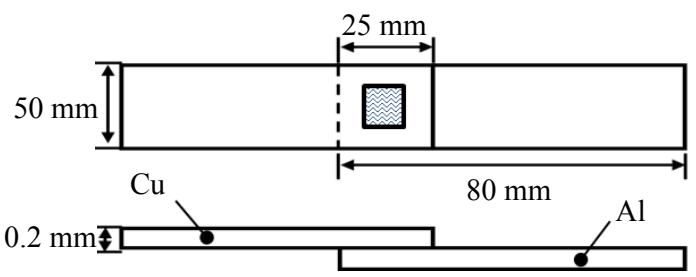

(a)
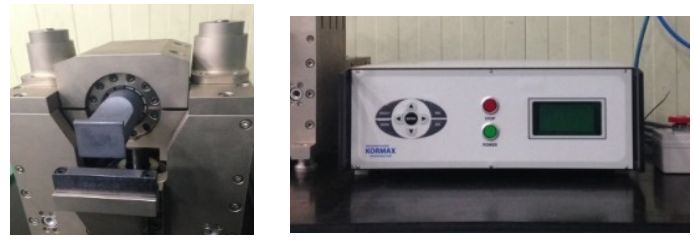

(b)

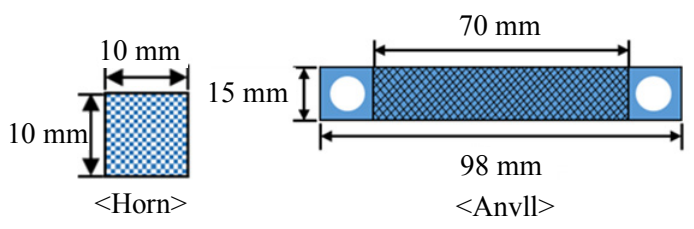

(c)

Fig. 2 Experimental set up. (a) Schematic diagram of fabricated sample, (b) Images of used ultrasonic welding machine, and (c) Designs of horn and anvil

Table 1 Ultrasonic welding variables used in experiment

\begin{tabular}{|c|c|}
\hline Variable & Parameter [Level] \\
\hline Welding time $(\mathrm{s})$ & $0.15,0.2,0.25,0.30,0.35,0.40[6$ levels] \\
\hline Clamping pressure $(\mathrm{MPa})$ & $0.2,0.3,0.4[3$ levels] \\
\hline Amplitude $(\mu \mathrm{m})$ & $24,29.5,33[3$ levels $]$ \\
\hline Joint type & Overlap \\
\hline
\end{tabular}

length of the surface indentation formed after ultrasonic welding, and indentation depth was quantified via crosssectional analysis and a non-contact three-dimensional measuring machine. At least six pieces of data were derived from the fabricated specimens and were averaged to present the width, length, and indentation depth. A tensile-shear test was performed with a head speed of 3 $\mathrm{mm} / \mathrm{min}$, and the results were presented as averages of the three specimens for each condition.

\section{Experimental results and discussion}

\subsection{Change in indentation shape with experimental variables}

The shape of the indentation on the contact surface of the material and ultrasonic tool changed in accordance with the experimental variables. Fig. 3 shows the indentation images with different welding times at a clamping pressure of $0.4 \mathrm{MPa}$ and amplitude of $24 \mu \mathrm{m}$. At short welding time condition, the indentations in the oxygen-free copper surface exhibited were relatively longer in the transverse direction due to transverse vibration. However, as time progressed, the lengths in

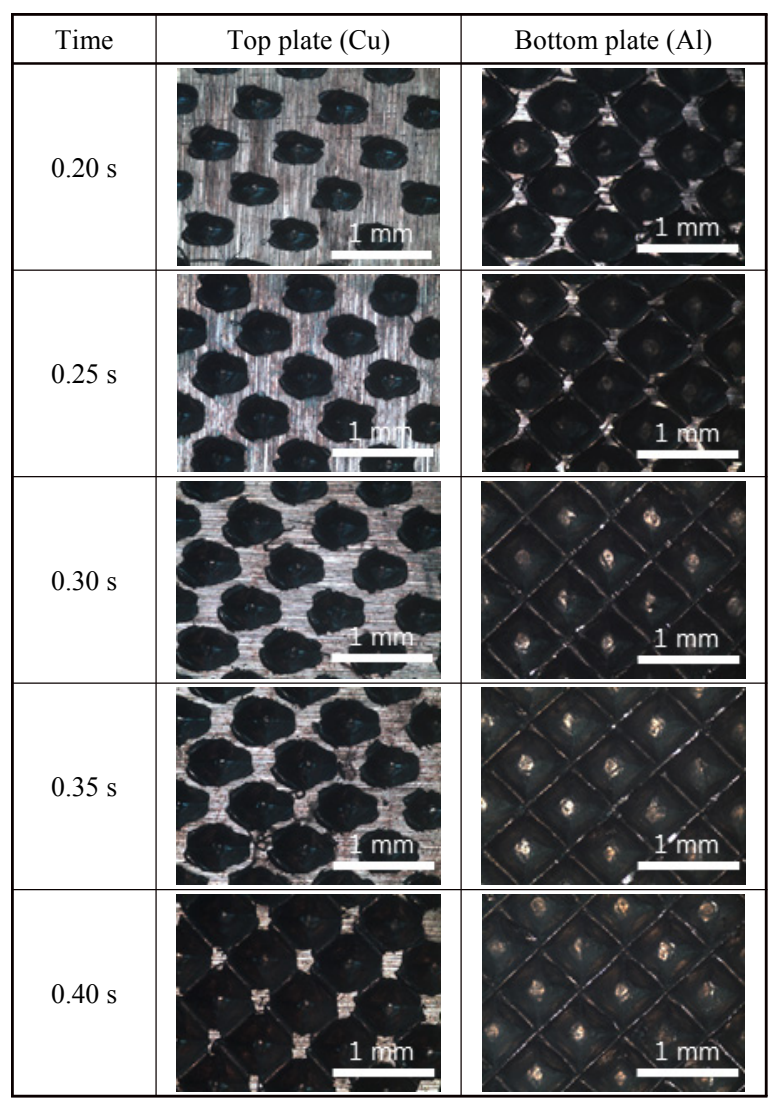

Fig. 3 Images of surface appearance corresponding to the welding time and substrates. The specimens were fabricated under a force of $0.4 \mathrm{MPa}$ and amplitude of $24 \mu \mathrm{m}$ 


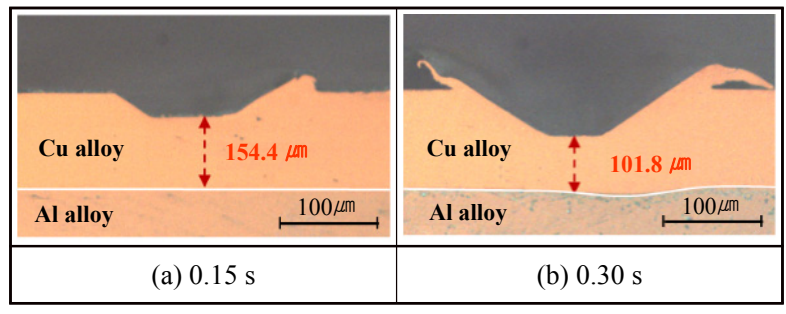

Fig. 4 Macro-sectional images of the ultrasonic welds at differential welding times. (a) $0.15 \mathrm{~s}$, and (b) $0.30 \mathrm{~s}$ (fixed welding condition; force of $0.2 \mathrm{MPa}$ and amplitude of $33 \mu \mathrm{m})$

the longitudinal and transverse directions became similar. In contrast, the aluminum surface indentations exhibited no large changes in shape after $0.25 \mathrm{~s}$. As the horn and anvil have a quadrangular pyramid shape, the surface indentation area has a tendency to increase in proportion to the square of the indentation depth (Fig. 4). The change in indentation depth in accordance with welding variables is summarized in Figs. 5 and 6. As shown in Fig. 5, the indentations formed on the oxygen-free copper surface were approximately $60 \mu \mathrm{m}$ for short welding time but increased to $120 \mu \mathrm{m}$ for longer time. In addition, indentations were deep even for short welding times as the amplitude increased. However, the effect of clamping pressure on indentation depth was unclear, although the indentations were expected to be deeper for increasing pressures. At a force of $0.4 \mathrm{MPa}$ and amplitude of $29.5 \mu \mathrm{m}$, the indentation depth was shallow compared to that at low pressure conditions. This proves that the increasing pressure enhanced the frictional force between the tool and substrate. Therefore, the applied external force was exhausted and the force transfer in the thickness direction was insufficient. On the other hand, changes in indentation depth on the aluminum substrate surface could be neglected, except for an amplitude of $24 \mu \mathrm{m}$ as shown in Fig. 6. In most cases, the indentation depths converged to approximately $110 \mu \mathrm{m}$.

\subsection{Change in joint strength according to experimental variables}

In general, mechanical properties are affected by welding variables such as clamping pressure, welding time, and vibration width. As shown in Fig. 7, the fracture strength tended to increase with an increase in welding time, and higher strengths were measured under large amplitudes even for shorter welding times. However, the effect of clamping pressure on strength was not clear. This trend matched the changes in indentation depths formed on the oxygen-free copper surface shown in Fig. 5.

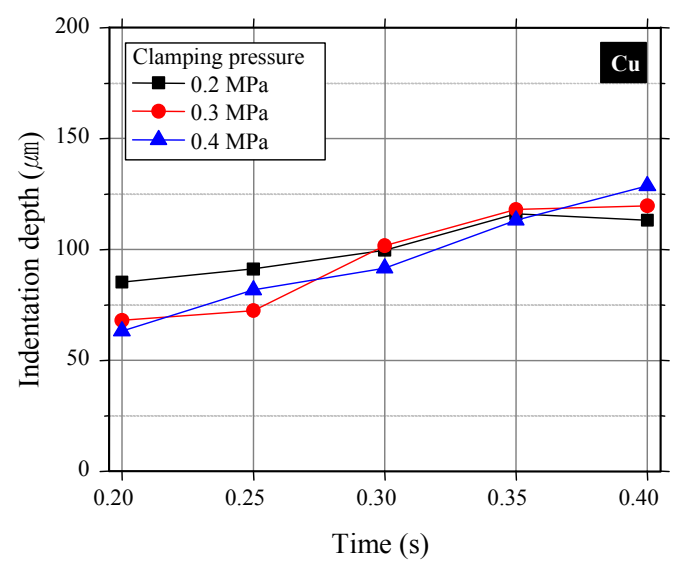

(a) $24 \mu \mathrm{m}$

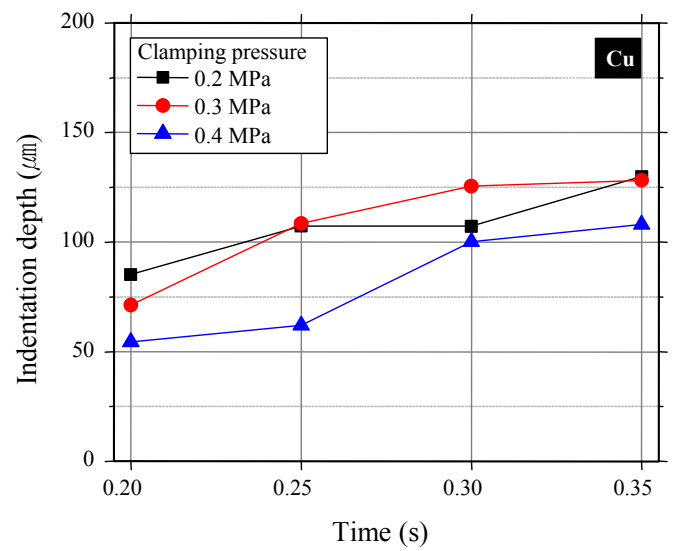

(b) $29.5 \mu \mathrm{m}$

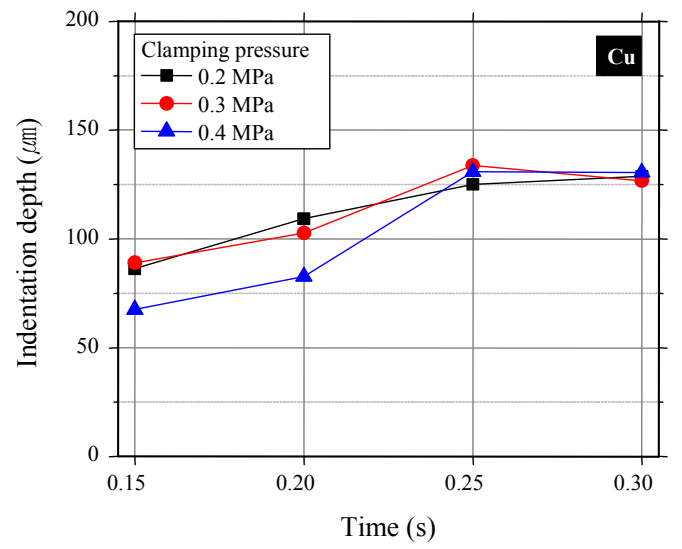

(c) $33 \mu \mathrm{m}$

Fig. 5 Indentation depth measurement on $\mathrm{Cu}$ substrate using non-contact measuring machine according to the welding variable. At amplitude of (a) $24 \mu \mathrm{m}$, (b) $29.5 \mu \mathrm{m}$, and (c) $33 \mu \mathrm{m}$

The frictional heat generated at the contact interface and the pressure of the horn/anvil penetrating the substrate are the driving forces that generate a bond in ultrasonic welding. As the aluminum indentations were similar under all conditions, the increase in strength can be attributed to the change in penetration depth in oxygen-free copper.

Fig. 8 shows the correlation between the joint fracture 


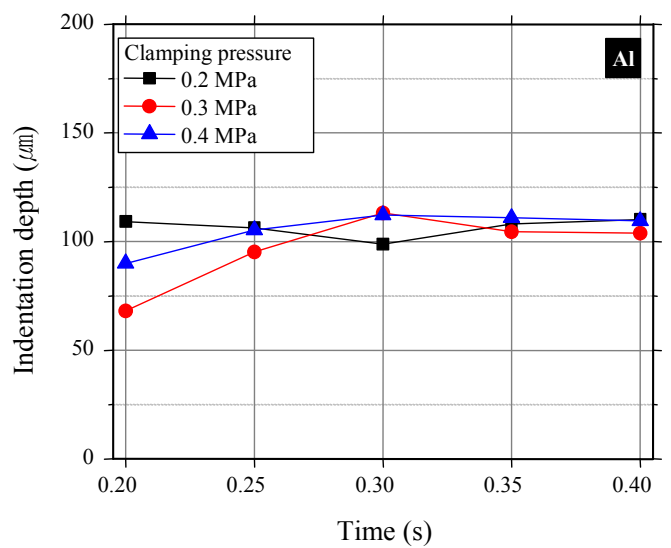

(a) $24 \mu \mathrm{m}$

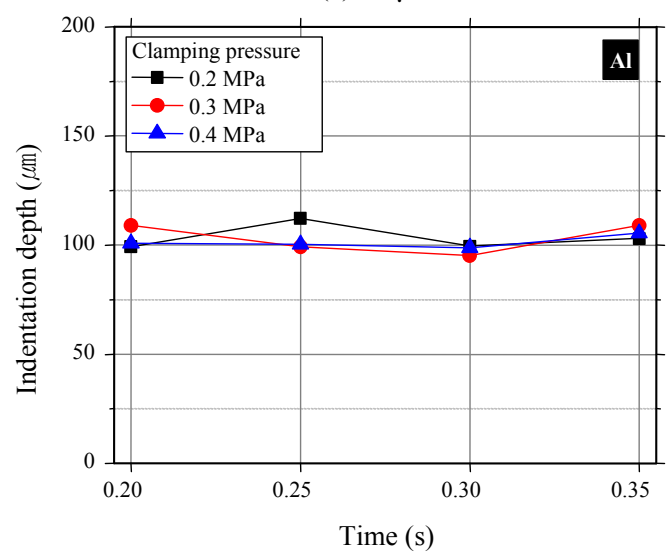

(b) $29.5 \mu \mathrm{m}$

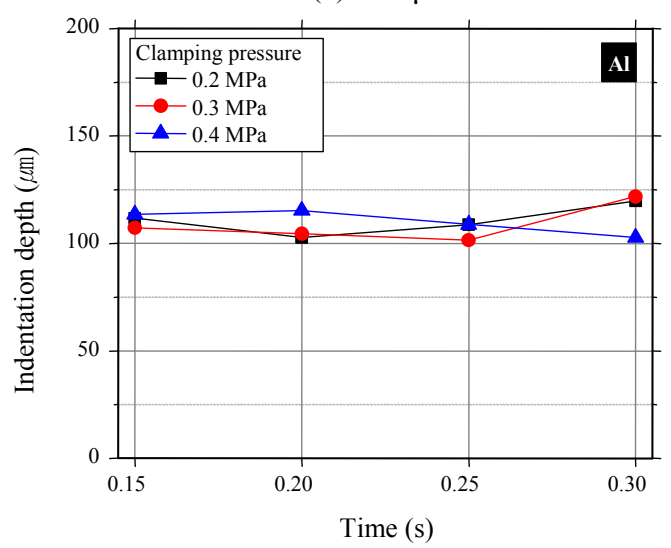

(c) $33 \mu \mathrm{m}$

Fig. 6 Indentation depth measurement on $\mathrm{Cu}$ substrate using non-contact measuring machine according to the welding variable. At amplitude of (a) $24 \mu \mathrm{m}$, (b) $29.5 \mu \mathrm{m}$, and (c) $33 \mu \mathrm{m}$

strength and indentation depth. Though the indentation depth on the aluminum substrate was relatively constant, the fracture strength greatly varied. This indicated that the indentation depth on the aluminum substrate is independent of changes in strength. In contrast, the fracture strength tended to increase as the indentation formed on the oxygen-free copper substrate deepened.

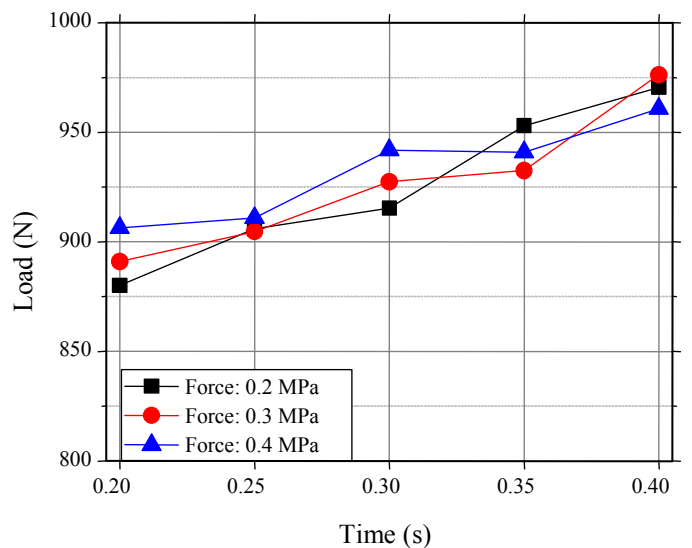

(a) $24 \mu \mathrm{m}$

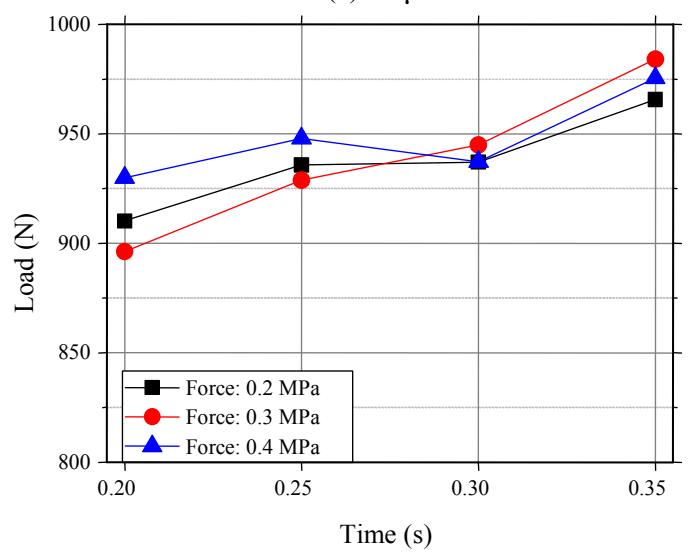

(b) $29.5 \mu \mathrm{m}$

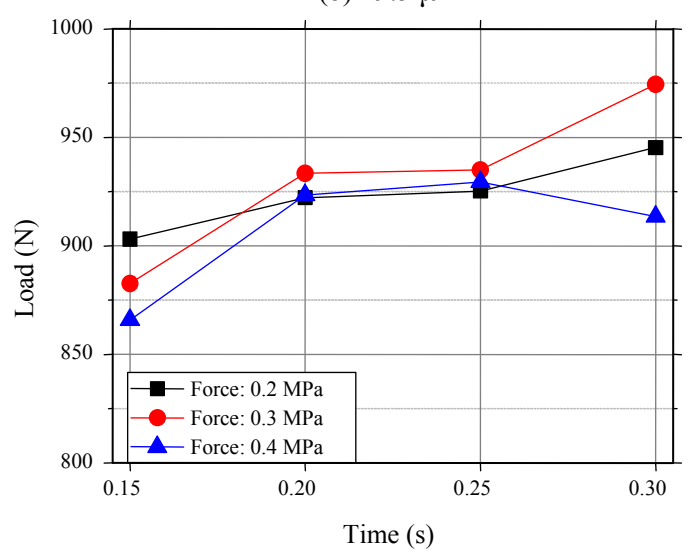

(c) $33 \mu \mathrm{m}$

Fig. 7 Measured tensile-shear load according to the welding variable. At amplitude of (a) $24 \mu \mathrm{m}$, (b) $29.5 \mu \mathrm{m}$, and (c) $33 \mu \mathrm{m}$

\subsection{Prediction of theoretical fracture strength}

According to the tensile-shear test on the ultrasonically welded dissimilar joint specimen, fractures occurred along the indentation boundary in the aluminum substrate, as shown in Fig. 9. This is due to the low strength of aluminum and the stress concentration formed by knurl penetrates, since fracture typically occurs in the most vulnerable areas.

Journal of Welding and Joining, Vol. 38, No. 3, 2020 
The principle of conservation of energy dictates that mass must be conserved during the welding process. Therefore, the volume that the knurl penetrates into the substrate $\left(\mathrm{m}_{1}\right)$ must equal the amount pushed out to the around $\left(\mathrm{m}_{2+} \mathrm{m}_{3}\right)$ (Fig. $\left.10(\mathrm{c})\right)$. It means that there is no loss of cross-sectional area regardless of penetration depth of knurl. As a result, when the space between the knurls is completely filled, the penetration depth no longer increases and converges to a certain value, as measured above.

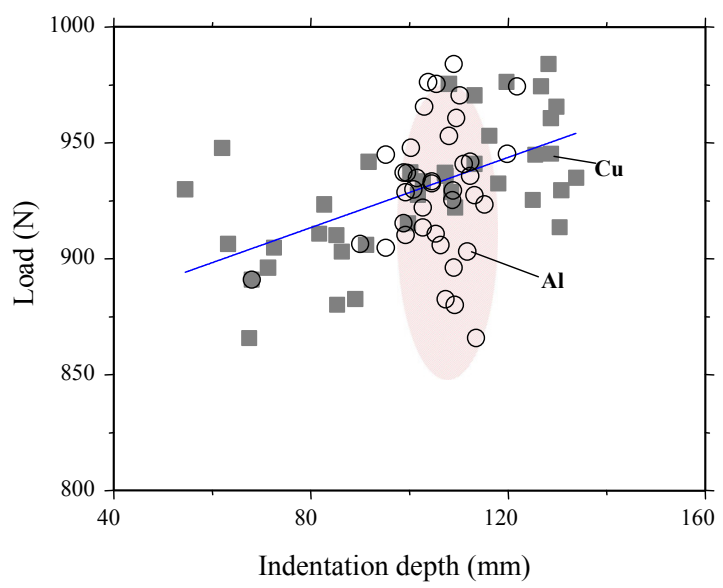

Fig. 8 Relationship between failure load and indentation depth depending on the substrates
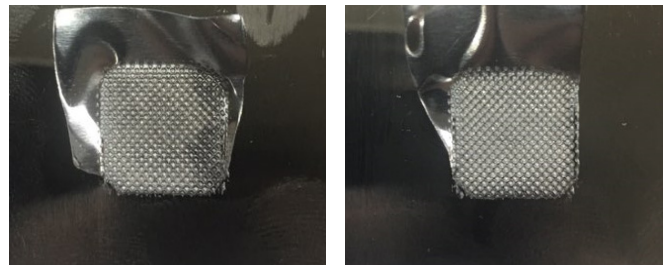

Fig. 9 Images of ruptured specimen after tensile-shear test

\begin{tabular}{|l|l|l|l|}
\hline & $\mathrm{X}$ & $\mathrm{Y}$ \\
\hline Horn & 0.85 & 0.22 \\
\hline Anvil & 0.85 & 0.22 \\
\hline
\end{tabular}

(a)

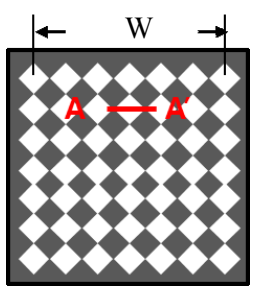

(b)

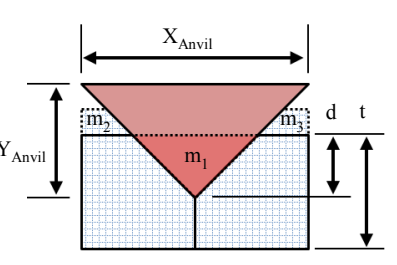

(c)
Fig. 10 (a) Definition of knurl dimension, (b) schematic diagrams of indentation mark, and (c) sectional images indicated in Fig. 10(b) (where $t$ is thickness of substrate, $\mathrm{d}$ is indentation depth, $\mathrm{W}$ is effective width, $\mathrm{X}$ and $\mathrm{Y}$ is dimensions of horn and envil)

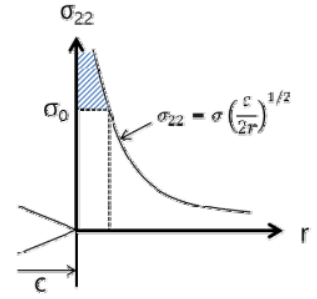

(a)

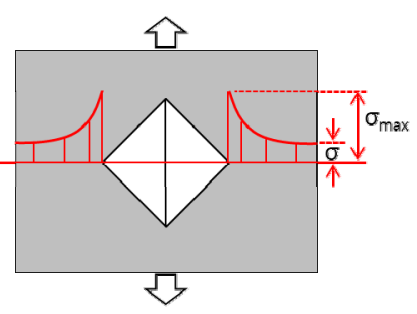

(b)
Fig. 11 (a) Definition of dimension, (b) Schematic diagrams of indentation mark, and (c) Sectional images indicated in Fig. 10

Because the stress is concentrated at the tip of the knurl, a cold-lapped (unbonded) joint interface can form next to the knurl, and act as a crack tip inside the joint $^{11)}$. In addition, the indentation boundary of the fracture, which is an interface contiguous with the unjointed part, can be treated as a sharp crack tip. Plastic deformation commonly occurs even at low stresses near crack tips. This is called fracture toughness (Fig. 11). A concentrated stress near the knurl can be expressed as in Eq. $1^{12,13)}$. Since it has a wide bonding interface compared to its thickness, a plane stress condition can be assumed. The above assumption justifies the summarization shown in Eqs. 2 and 3 (where $\theta=$ $0)$. It means that when the material is locally under tension, it can undergo plastic deformation at less than $70 \%$ of the base material strength. The measured fracture strength was $900-950 \mathrm{~N}$, which is $62-65 \%$ of the tensile strength of aluminum substrate, and similar to the value predicted by the equation.

$$
\begin{aligned}
& \sigma_{22}=\sigma\left(\frac{c}{2 r}\right)^{1 / 2} \cos \frac{\theta}{2}\left(1+\sin \frac{\theta}{2} \sin \frac{3 \theta}{2}\right) \\
& \sigma_{22}=\sigma\left(\frac{c}{2 r}\right)^{1 / 2} \\
& \sigma_{22}=\frac{1}{\sqrt{2}} \sigma_{B M}(i f, c \approx r)
\end{aligned}
$$

While some studies have reported that physical properties change due to indentation deformation, no singularity could be found based on the hardness test in the experiment (Fig. 12). Some differences are predicted in accordance with the material used or degree of hardening. Deformation hardening under the indentation is important because the indentation acts as a path of the fracture. If a hardness change has occurred, it is necessary to modify $\sigma_{\mathrm{BM}}$ in Eq. 3 considering the changes in hardness under the indentation. 


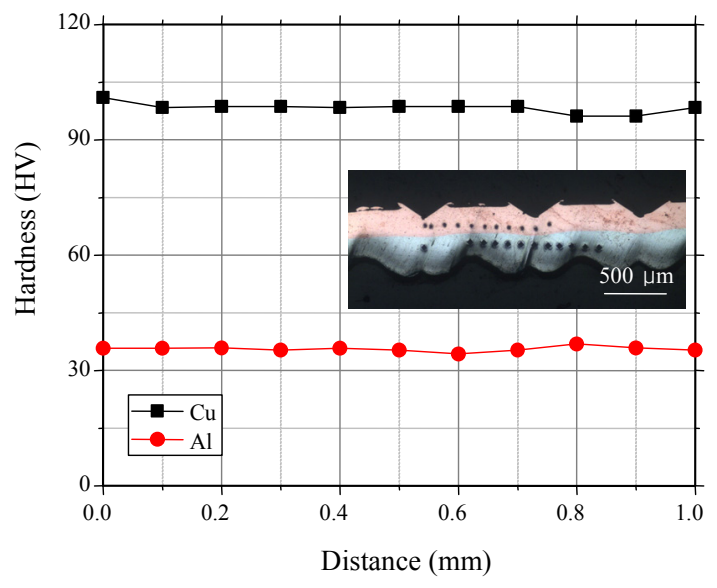

Fig. 12 Hardness profile of ultrasonic welds, which was fabricated under a force of $0.3 \mathrm{MPa}$, amplitude of $29.5 \mu \mathrm{m}$, and welding time of $0.3 \mathrm{~s}$

\section{Conclusions}

This study investigated the effect of process variables on the formation of indentations in an ultrasonic welded aluminum/oxygen-free copper dissimilar joint and suggested the theoretical maximum fracture strength. A non-contact measuring device was used to digitize the indentation depth. The results confirmed that the indentation depth converged to a certain value due to the knurl height.

The indentation depth in the oxygen-free copper surface increased proportionally with the welding time, and the fracture strength also tended to increase. Fractures occurred at the indentation boundary of the aluminum substrate having low fracture toughness.

Ultrasonic welding has characteristics that makes it possible to avoid the formation of intermetallic compounds between two substrates. However, it is necessary to design the safety factor in consideration of fracture toughness and the fracture path.

\section{Acknowledgments}

This research was supported by Basic Science Research Program through the National Research Foundation of Korea (NRF) funded by the Ministry of Education (grant: 2019R1F1A1057315)

ORCID: Minjung Kang: https://orcid.org/0000-0003-1894-4301 ORCID: Kyuhong Lee: https://orcid.org/0000-0003-2425-2192

\section{References}

1. S. Chu and A. Majumdar, Opportunities and challenges for a sustainable energy future, nature, 488(7411) (2012) 294. https://doi.org/10.1038/nature11475

2. S. S. Lee, T. H. Kim, S. J. Hu, W. W. Cai and J. A. Abell, Joining technologies for automotive lithium-ion battery manufacturing: A review, in ASME 2010 international manufacturing science and engineering conference, (American Society of Mechanical Engineers) City, (2010) 541-549. https://doi.org/10.1115/MSEC2010-34168

3. A. Das, D. Li, D. Williams and D. Greenwood, Joining Technologies for Automotive Battery Systems Manufacturing, World Electric Vehicle J. 9(2) (2018) 22. https://doi.org/10.3390/wevj9020022

4. M. Sahin, Joining of aluminium and copper materials with friction welding, Int. J. adv. Manuf. Technol. 49(5-8) (2010) 527-534. https://doi.org/10.1007/s00170-009-2443-7

5. C. Tan, Z. Jiang, L. Li, Y. Chen and X. Chen, Microstructural evolution and mechanical properties of dissimilar Al-Cu joints produced by friction stir welding, Mater. Des. 51 (2013) 466-473. https://doi.org/10.1016/j.matdes.2013.04.056

6. S. J. Lee, J. D Kim and S. Katayama, A study on the chracteristic of weld joint and tensile fracture of SUS304 and $\mathrm{Cu}$ high-speed dissimilar lap welds by single mode fiber laser, J. Weld.Join. 32(6) (2014) 56-63. https://dx.doi.org/10.5781/JWJ.2014.32.6.56

7. D. Lee and W. Cai, The effect of horn knurl geometry on battery tab ultrasonic welding quality: 2D finite element simulations, J. Manuf. Processes, 28 (2017) 428441.

https://doi.org/10.1016/j.jmapro.2017.04.009

8. L. Xi, M. Banu, S. J. Hu, W. Cai and J. Abell, Performance prediction for ultrasonically welded dissimilar materials joints, J. Manuf. Sci. Eng. 139(1) (2017) 011008. https://doi.org/10.1115/1.4033692

9. A. Das, I. Masters and D. Williams, Process robustness and strength analysis of multi-layered dissimilar joints using ultrasonic metal welding, Int. J. adv. Manuf. Technol. 101 (2019) 881-900. https://doi.org/10.1007/s00170-018-2936-3

10. N. Shen, A. Samanta, H. Ding and W. W. Cai, Simulating microstructure evolution of battery tabs during ultrasonic welding, J. Manuf. Processes, 23 (2016) 306-314. https://doi.org/10.1016/j.jmapro.2016.04.005

11. S. S. Lee, T. H. Kim, S. J. Hu, W. W. Cai, J. A. Abell and J. Li, Characterization of joint quality in ultrasonic welding of battery tabs, J. Manuf. Sci. Eng. 135(2) (2013) 021004 . https://doi.org/10.1115/1.4023364

12. G. R. Irwin, Analysis of stresses and strains near the end of a crack traversing a plate (1997).

13. H. M. Westergaard, Bearing pressures and cracks, Trans AIME, J. Appl. Mech. 6 (1939) 49-53. 